\title{
PENGEMBANGAN KEPERCAYAAN DIRI MELALUI METODE SHOW AND TELL PADA ANAK
}

\author{
Thafa Nazla ${ }^{1}$; Nila Fitria ${ }^{1}$ \\ ${ }^{1}$ Program Studi Pendidikan Guru Pendidikan Anak Usia Dini, Fakultas Psikologi dan Pendidikan, \\ Universitas Al Azhar Indonesia, Jalan Sisingamangaraja Kebayoran baru, Jakarta Selatan 12110 \\ Penulis untuk Korespondensi/ E-mail: nilafitria@uai.ac.id.
}

\begin{abstract}
Abstrak - Kepercayaan diri merupakan suatu fikiran atau perasaan maupun pemahaman yang dimiliki anak untuk melakukan tindakan dan kemauan yang positif dan berani untuk memecahkan masalah. Untuk mendukung pengembangan kepercayaan diri tersebut harus sekolah harus membuat sebuah program yaitu salah satu nya adalah show and tell. Show and tell merupakan kegiatan dimana anak dapat membawa barang yang disukainya ataupun yang dianggapnya menarik lalu diceritakan di depan teman-temannya mengenai informasi seputar benda tersebut. Penelitian ini bertujuan untuk melihat pengembangan kepercayaan diri anak melalui metode show and tell usia 4 tahun yang dilakukan di Kidscenter Preschool Bintaro Utama 9 Pondok Pucung Tangerang.Penelitian ini menggunakan metode penelitian kualitatif dengan pendekatan kualitatif deskriptif. Teknik pengmpulan data yang digunakan adalah wawancara,observasi dan dokumentasi. Sumber data dalam penelitian ini adalah kepala sekolah,guru kelas, dan 3 orang anak preschool. Hasil penelitian ini menunjukan bahwa Pengembangan kepercayaan diri melalui metode show and tell pada anak usia 4 tahun di Kidcenter Preschool Bintaro Utama 9 Pondok Pucung sudah dilakukan dengan baik. Hal tersebut karena proses pelaksanaan show and tell dilakukan dengan baik. Guru menjelaskan mengenai kegiatan yang akan dilakukan lalu guru mmberikan contoh kepada anak-anak secara klasikal lalu anak akan maju untuk melakukan show and tell dengan kemauannya sendiri.
\end{abstract}

Kata Kunci: Pengembangan kepercayaan diri, Show and tell, anak usia 4 tahun.

Abstract - Self-confidence is a thought or feeling or understanding that children have to take positive and courageous action and willingness to solve problems. To support the development of selfconfidence, schools must make a program, one of which is show and tell. Show and tell activities where children can bring items they like or that come interesting and then tell them in front of their friends about information about these objects. This study aims to see the development of children's self-confidence through methods. Show and tell the age of 4 years which is done at Kidscenter Preschool Bintaro Utama 9 Pondok Pucung Tangerang. This research uses qualitative research methods with a descriptive qualitative approach. The data collection techniques used were interviews, observation and documentation. Sources of data in this study were the principal, classroom teachers, and 3 preschool children.The results showed that the development of self-confidence through the method of showing and telling children aged 4 years at Kidccenter Preschool Bintaro Utama 9 Pondok Pucung has been done well. This is because the process of implementing the show is well done. The teacher explains the activities that will be carried out, then the teacher gives an example to the children classically, then the children will come forward to do a show and tell with their own accord.

Keywords: Self-confidence development, show and tell, 4 year olds 


\section{PENDAHULUAN}

$\mathrm{A}$ nak usia dini adalah individu yang sedang mengalami proses pertumbuhan dan perkembangan yang pesat bahkan dikatakan oleh Hurlock sebagai lompatan perkembangan, karena itu usia dini dikatakan sebagai usia emas (golden age) yaitu usia yang berharga dibanding usia selanjutnya Undangundang sistem pendidikan nasional (sisdiknas) Nomor 20 tahun 2003 mengemukakan bahwa: "Pendidikan anak usia dini adalah suatu upaya pembinaan yang ditujukan kepada anak sejak lahir sampai usia enam tahun yang dilaksanakan melalui pemberian rangsangan pendidikan untuk membantu pertumbuhan dan perkembangan jasmani dan rohani agar anak memiliki kesiapan dalam memasuki pendidikan lanjut."

Terdapat pada Permendikbud Nomor 137 Tahun 2014 tentang Standar Pendidikan Anak Usia Dini. Rasa percaya diri yang dimaksud adalah dapat memperlihatkan kemampuan diri untuk menyesuaikan dengan situasi. Kepercayaan diri tidak dibawa sejak lahir. Kepercayaan diri mulai ditumbuhkan dan distimulai sejak dini. Kepercayaan diri merupakan hal yang penting bagi anak untuk menapaki roda kehidupan. Kepercayaan diri akan menjadi modal untuk kesuksesan anak kelak. Anak akan lebih cepat bergaul, lebih cepat menguasai keahlian dan lebih siap menghadapi masalah. Anak yang memiliki kepercayaan diri maka ia akan mampu untuk menguasai bidang tertentu dan lebih mudah menyerap hal yang diinformasikan padanya dikemudian hari. Saat dewasa anak tersebut akan lebih mampu menghadapi berbagai tantangan kehidupan secara maksimal tanpa meminta bantuan yang berlebihan pada orang lain. (Aprianti, 2010: 15).

Menurut Hakim (2005: 6), kepercayaan diri adalah keyakinan seseorang terhadap segala aspek kelebihan yang dimilikinya dan keyakinan tersebut membuatnya merasa mampu untuk bisa mencapai berbagai tujuan di dalam hidupnya. Senada dengan Hakim, Lie (2003: 4) berpendapat bahwa percaya diri berarti yakin akan kemampuannya untuk menyelesaikan suatu pekerjaan dan masalah. Sementara Fatimah (2006: 149) mendefinisikan kepercayaan diri sebagai sikap positif seorang individu yang memampukan dirinya untuk mengembangkan penilaian positif, baik terhadap diri sendiri maupun terhadap lingkungan/situasi yang dihadapi.

Ciri -ciri anak yang memiliki kepercayaan diri yang tinggi menurut Yoder dan Proctor (1988:

4) yakni:

1. Self confidence is the active (percaya diri adalah aktif)

2. Effective expression of inner feeling of self worth (ekspresi dari dalam mengenai harga diri)

3. Self Esteem (Harga diri yang tinggi)

4. Self understanding (pemahaman harga diri yang baik)

Adapun dampak negatif yang dapat terjadi jika anak kurang rasa percaya diri seperti menurut Gunarsa (1991) mengatakan bahwa sikap anak yang pasif, rendah diri, mempunyai kecenderungan agresif dan lain sebagainya hal ini merupakan faktor yang dapat menghambat anak dalam berprestasi yang diharapkan. Anakanak ini biasanya dikarakteristikkan sebagai anak yang mempunyai konsep serta harga diri yang kurang baik dan juga tampak kurang ada rasa aman di dalam dirinya untuk dapat berprestasi dengan baik. Maka dapat dikeatahui bahwa anak yang kurang percaya diri akan memiliki peluang yang besar untuk gagal dimasa depan.

Berdasarkan hasil observasi yang dilakukan pada bulan januari tahun 2020 di KidsCenter Preschool masih banyak anak yang kurang percaya diri untuk tampil di depan kelasnya. Anak yang kurang percaya diri tidak mau maju kedepan saat guru memanggil untuk berpartisipasi di kegiatan dalam kelasnya contohnya seperti guru memanggil anak bernyanyi di depan teman-temannya, bercerita di depan kelas maupun saat guru meminta anak bermain dengan teman kelompoknya.

Di Kidscenter preschool ini sudah menerapkan kegiatan bercerita, anak diminta untuk bercerita di depan teman-temannya menggunakan sebuah buku namun hal ini kurang efektif dilakukan karena anak-anak tidak terlihat antusias saat bercerita menggunakan buku, Salah satu metode yang dapat digunakan untuk pengembangan kepercayaan diri anak yang dilakukan sekolah adalah melalui metode Show and Tell. Metode Show and Tell adalah kegiatan dimana anak bercerita di depan kelas mengenai 
barang ataupun mainan yang disukainya dan diceritakan kepada teman - teman dikelasnya.

Menurut Tilaar (2013: 103), show and tell adalah kegiatan yang mengutamakan kemampuan berkomunikasi sederhana.Tujuan kegiatan ini adalah melatih anak berbicara di depan kelas dan membiasakan anak peka terhadap hal-hal sederhana sehari-hari. Sementara Suyanto (2005: 145) menyatakan bahwa metode show and tell digunakan untuk mengungkap kemampuan, perasaan, dan keinginan anak. Setiap hari guru dapat meminta dua atau tiga orang anak untuk bercerita apa saja yang ingin diungkapkan. Saat anak bercerita, guru dapat melakukan asesmen pada anak tersebut. Guru dapat melanjutkan topik yang dibicarakan anak sebagai pembelajaran.

Di sisi lain, Musfiroh (2011: 5) mendefinisikan show and tell sebagai kegiatan yang menunjukkan sesuatu kepada audiens dan menjelaskan atau mendeskripsikan sesuatu itu. Lebih lanjut Musfiroh menuliskan bahwa terdapat beberapa jenis show and tell yang dapat diterapkan, yakni: Show and tell dengan benda pribadi; Show and tell dengan makanan; dan Show and tell dengan gambar dan foto.

Adapun manfaat penggunaan metode show and tell, menurut Laurie Patsalides dalam Musfiroh (2011), yaitu: Belajar berbicara dan menyimak; Antisipasi dan observasi; Praktik bercerita; Menggunakan kosakata; serta Meningkatkan rasa percaya diri

Sesuai dengan latar belakang masalah, maka tujuan penelitian ini adalah untuk menggambarkan proses pengembangan kepercayaan diri anak usia 4 tahun melalui metode show and tell di Kidscenter Preschool.

\section{METODE PENELITIAN}

Penelitian yang dilakukan di Preschool Kidscenter studio ini menggunakan metode kualitatif dengan pendekatan deskriptif. Kidscenter studio beralamat di Jalan Bintaro Utama 9 Blok JB 5 No. 4 Bintaro Jaya Sektor 9 pondok Pucung Tangerang. Waktu penelitian dilaksanakan pada Januari 2020 - Maret 2020. Subjek penelitian adalah adalah 3 anak dari kelas Kidcenter Preschool Bintaro Utama 9 Pondok Pucung. Terdiri dari 2 laki-laki dan 1 perempuan. Penelitian ini merupakan penelitian
Teknik penelitian yang digunakan adalah observasi; wawancara; dan dokumentasi. Sementara analisis data yang digunakan adalah reduksi data; display data; dan mengambil kesimpulan

\section{HASIL DAN PEMBAHASAN}

Berdasarkan hasil observasi terdapat 3 anak yang terlihat tinggi rasa percaya diri nya. Anak yang memiliki rasa percaya diri yang tinggi adalah AR, JN dan RY. Berikut dipaparkan hasil observasi pada ketiga subjek tersebut.

\section{Subjek 1}

Subjek yang pertama adalah AR, saat hari pertama pada tanggal 3 maret 2020. AR melakukan kegiatan show and tell dengan kemauannya sendiri. AR sudah membawa sebuah maianan mobil miliknya lalu diceritakan di depan teman-temannya guru membantu untuk AR dalam mengucapkan salam. AR menceritakan ciri-ciri mainan mobil yang dimilikinya lalu saat Ar kesulitan mennjawab pertanyaan dari temannya guru membantu AR untuk memberikan jawaban. Setelah Ar melakukan show and tell guru melakukan reward berupa pujian kepada AR agar Ar dan teman-teman yang menonton mau melakukan show and tell di kemudian hari.

\section{Subjek 2}

Subjek yang kedua adalah JN. Pada hari kedua tanggal 4 maret 2020, guru bertanya kepada murid-murid yang mau melakukan show and tell, lalu JN mengangkat tangannya dan berkata bahwa dia sudah membawa sebuah mainan masak-masakan miliknya. JN maju dan duduk di depan teman-temannya. JN didampingi oleh guru guna membantu JN menjelaskan seputar maiannya. Guru meminta JN untuk menunjukan maianannya dihadapan temannya satu persatu setelah itu teman-teman bertanya mengenai mainan JN. Guru meminta anak-anak yang lain untuk melakukan show and tell juga dikemudian hari seperti JN.

\section{Subjek 3}

Subjek yang ketiga adalah RY,pada tanggal 6 maret 2020 dipagi hari RY membawa sebuah buku miliknya lalu guru meminta RY untuk melakukan show and tell dengan bukunya. Saat 
show and tell dimulai RY menjelaskan

mengenai gambar yang ada di bukunya selanjutnya guru bertanya kepada RY ada apa saja didalam buku terserbut kemudian RY menjawab pertanyaan guru dan pertanyaan teman yang lain.setelah dilakukannya show and tell guru meminta anak-anak yang lain jika mempunyai buku seperti RY boleh dibawa untuk melakukan show and tell seperti yang dilakukan RY.

Kepercayaan diri menurut guru Kidccenter Preschool Bintaro Utama 9 Pondok Pucung adalah saat dimana anak mau dan bertindak dan melakukan sesuatu dengan berani tanpa rasa takut.Hal ini sesuai dengan pendapat yang dikemukakan Hakim (dalam Rahayu 2013: 63) kepercayaan diri adalah keyakinan seseorang terhadap segala aspek kelebihan yang dimilikinya dan membuat kemampuannya untuk mencapai berbagai tujuan hidup. Anak dapat dikatakan percaya diri apabila anak berani dan mampu melakukan kegiatan yang positif bagi dirinya.

Selanjutnya anak-anak yang percaya diri akan yakin saat melakukan kegiatan yang disukainya yaitu seperti bernyanyi ataupun olahraga, saat guru meminta murid untuk bernyanyi dan melakukan kegiatan olahraga seperti melompat anak tanpa ragu mau melakukannya hal ini sesuai dengan pendapat Marry (dalam Butolo 2013: 7) mengenai macam-macam percaya diri pada point ke tiga yaitu Self Efficacy yaitu anak mempunyai keyakinan pada sesuatu yang sedang dikerjakannya bahwa hasilnya akan bagus.

Anita Lie (dalam Ningsih, 2014: 8), ada beberapa karakteristik kepercayaan diri anak point ke enam yaitu memiliki keberanian untuk bertindak yang berarti anak mau melakukan sesuatu dengan berani tanpa rasa takut. Pemberian kegiatan-kegiatan di sekolah sangat berpengaruh guna membantu pengembangan kepercayaan diri anak salah satu kegiatan di Kidscenter Preschool Bintaro Utama 9 adalah kegiatan Show and tell sesuai dengan Seliti (2011: 12-13) mengenai Faktor-faktor yang mempengaruhi percaya diri, faktor eksternal point ke tiga yaitu lingkungan, adanya programprogram sekolah yang dapat menjadi sarana dalam meningkatkan kepercayaan diri anak.

Kegiatan show and tell yang dilakukan adalah anak menceritakan suatu kejadian ataupun

barang kesukaan yang dimilikinya di depan teman-temannya lalu anak-anak yang mendengarkan akan menyimak dan membuat pertanyaan yang diajukan kepada anak yang melakukan show and tell. Hal ini sesuai dengan definisi yang dikatakan Takdiroatun Musfiroh (2011: 5) yaitu show and tell merupakan kegiatan menunjukan sesuatu kepada audiens dan menjelaskan atau mendeskirpsikan hal tersebut

Anak-anak yang melakukan show and tell akan menentukan sendiri barang yang akan di tunjukan kedepan teman-temannya. Contohnya anak membawa mainan ataupun buku kesukaannya yang dibawa dari rumah, hal ini sesuai dengan yang dikatakan oleh Takdiroatun Musfiroh (2011: 34) bahwa saat penerapan Show and tell terdapat beberapa jenis show and tell yang dapat diterapkan yaitu pada point pertama show and tell dengan benda pribadi, anak dapat membawa benda-benda pribadi untuk digunakan saat show and tell.

Pada saat anak melakukan show and tell anak akan belajar memperkenalkan diri, menyebutkan ciri-ciri pada suatu benda dan anak yang lain akan belajar untuk menyimak dan bertanya hal ini akan membantu anak dalam meningkatkan percaya diri, sesuai dengan pendapat Laurie Ptsalides (dalam Musfiroh, 2011: 8-9), mengenai manfaat show and tell berbagai manfaat tersebut yaitu anak belajar bercerita, menyimak dan meningkatkan percaya diri. Terkait dengan manfaat yang dikemukakan oleh Laurie Patsalides mengenai meningkatkan percaya diri hal ini dipertegas oleh Zingher (2011: 44) yang menyatakan bahwa saat anak melakukan show and tell akan menjadi momen yang bersinar bagi anak karena kepercayaan dirinya meningkat.

\section{SIMPULAN DAN SARAN}

Simpulan dari penelitian ini adalah bahwa pengembangan kepercayaan diri melalui metode show and tell pada anak usia 4 tahun di Kidccenter Preschool Bintaro Utama 9 pondok pucung sudah dilakukan dengan baik. Hal tersebut karena proses pelaksanaan show and tell dilakukan dengan baik. Guru menjelaskan mengenai kegiatan yang akan dilakukan lalu guru memberikan contoh kepada anak-anak secara klasikal lalu anak akan maju untuk 
melakukan show and tell dengan kemauannya

sendiri. Anak yang melakukan show and tell akan didampingi oleh guru guna membantu saat anak kesulitan menyampaikan sebuah kalimat dalam penjelasan barang yang di presentasikan di depan teman-temannya. Anak - anak yang lain akan menyimak lalu memberi pertanyaan kepada anak yang melakukan show and tell. Setelah itu anak yang berani melakukan show and tellakan di beri reward berupa pujian dan tepuk tangan dari guru sebagai bentuk penguatan agar anak-anak yang lain mau melakukan show and tell dikemudian hari.

Adapun saran yang dapat diberikan bagi guru adalah agar guru dapat lebih memotivasi anak untuk melakukan show and tell dan guru melakukan reward berupa pemberian sticker pada anak yang sudah melakukan show and tell. Sementara bagi kepala sekolah agar memberikan pelatihan bagi guru agar dapat menjadi fasilitator untuk memotivasi anak melakukan lebih banyak kegiatan.

\section{DAFTAR PUSTAKA}

Butolo, H. (2013). Meningkatkan rasa percaya diri melalui kegiatan menari di tk sukma kecamatan kabila bone kabupten bone bolango.

Fatimah, E. (2010). Psikologi perkembangan (perkembangan peserta didik). Bandung: Pustaka Setia.

Gunarsa, S.D. (1991). Psikologi praktis: anak, remaja, dan keluarga. Jakarta: PT. BPK Gunung Mulia.

Tilaar, H.A.R. (2013). Media pembelajaran aktif. Bandung: Nuansa Cendekia.

Hurlock, E.B. (2011). Psikologi perkembangan: suatu pendekatan sepanjang rentang kehidupan. Jakarta: Erlangga.

Jean, Y., \& William, P. (1988). The selfconfident child. New York: The United States of America, Facts on file publications.

Kementerian Pendidikan dan Kebudayaan. (2015). Peraturan Menteri Pendidikan dan Kebudayaan Republik Indonesia Nomor 137 Tahun 2013 tentang standar nasional pendidikan anak usia dini. Jakarta.

Lie, A. (2003). 101 Cara menumbuhkan rasa percaya diri anak. Jakarta: Gramedia.

Musfiroh,T. (2011). Show and tell Edukatif untuk pengembangan empati afilasi resolusi konflik dan kebiasaan positif. Yogyakarta: Sleman.

Ningsih, T. (2014). Implementasi pendidikan karakter. Purwokerto: Stain Press.

Rahayu, A.Y. (2013). Menumbuhkan kepercayaan diri melalui kegiatan bercerita. Jakarta: Indeks.

Republik Indonesia.Undang-undang Nomor 20 Tahun 2005 tentang sistem pendidikan nasional. Jakarta.

Suyanto, S. (2005). Dasar-dasar pendidikan anak usia Dini. Yogyakarta: Hikayah Publishing.

Seliti, B. (2011). Peningkatan kepercayaan diri siswa melalui cooperative learning tipe numbered head together (nht) dalam pembelajaran matematika (penelitian tindakan kelas di SMP Negeri 4 Kota Tangerang Selatan). Skripsi. Fakultas Ilmu Tarbiyah dan Keguruan UIN Syarif Hidayatullah Jakarta.

Hakim, T. (2005). Mengatasi rasa tidak percaya diri. Jakarta: Puspa Swara.

Zingher. (2011). Unexpected show and tell. United States: Libraries. Unlimited, Inc. 